\title{
Role of microRNA-503 in the suppression of osteosarcoma cell proliferation and migration via modulation of fibroblast growth factor 2
}

\author{
BING WU and WENZHI BI \\ Department of Orthopaedics, Chinese PLA General Hospital, Beijing 100853, P.R. China
}

Received October 24, 2014; Accepted August 05, 2015

DOI: $10.3892 / \mathrm{mmr} .2015 .4399$

\begin{abstract}
The present study aimed to investigate the expression levels of microRNA (miR)-503 in osteosarcoma (OS), as well as to assess the effects and underlying mechanisms of miR-503 on cell proliferation, apoptosis, migration and invasion of OS cells. Reverse transcription-quantitative polymerase chain reaction (RT-qPCR) was used to determine the expression levels of miR-503 in OS and adjacent normal bone tissue samples. Proliferation, apoptosis, migration and invasion assays were performed to determine the effects of miR-503 on OS cells. The expression levels of miR-503 were significantly decreased in OS tissue samples, as compared with normal tissue samples $(\mathrm{P}<0.0001)$. Upregulation of miR-503 significantly inhibited proliferation and induced cell apoptosis, as compared with the negative controls. The results of the present study also demonstrated that miR-503 significantly decreased the migration and invasion ability of the OS cells, which may be mediated by the inhibition of fibroblast growth factor 2 (FGF2). In conclusion, the present study demonstrated that expression of miR-503 was involved in the inhibition of cellular proliferation, and induced apoptosis of the OS cells. In addition, miR-503 was able to inhibit the migration and invasion ability of OS cells, likely via the inhibition of FGF2 expression.
\end{abstract}

\section{Introduction}

Osteosarcoma (OS), with an incidence of 4.4 per million worldwide, is the most common type of primary malignant bone tumor in children and adolescents, and accounts for $60 \%$ of all malignant childhood bone tumors (1). A first major peak of morbidity occurs in patients between 10 and 20 years of age,

Correspondence to: Dr Wenzhi Bi, Department of Orthopaedics, Chinese PLA General Hospital, 28 Fuxing Road, Beijing 100853, P.R. China

E-mail: wzbi_2014@163.com

Key words: osteosarcoma, microRNA-503, fibroblast growth factor 2 and the second, smaller peak is observed in patients $>50$ years of age (1). OS usually occurs following rapid bone growth, such as that observed in the proximal tibia, distal femur and proximal humerus, and is characterized by the direct formation of immature bone and osteoid tissue. The majority of OS tumors are of high grade and result in pulmonary metastases. The five-year overall survival rate is currently $70 \%(2,3)$. However, though significant advances have been made in OS treatment strategies, patients exhibiting metastases or recurrent OS tumors still have a poor prognosis, and account for $30-35 \%$ of all patients with OS $(2,4)$. The survival rates are even lower in young patients with OS (18-30 years), due to the increased rates of metastasis (5). Therefore, it is important that novel OS targets and therapeutic approaches are identified.

MicroRNAs (miRNA or miR) are a class of endogenously expressed, non-coding small ( 22 nucleotides) RNA molecules, which exhibit a high degree of structure and function conservation in metazoa (6-8). To date, a total of 450 miRNAs have been found in mammalian cells; however, $\geq 1,000$ miRNAs remain uncharacterized $(9,10)$. The biological functions of miRNAs have yet to be fully elucidated, but previous studies have demonstrated that they are involved in cell growth, apoptosis, differentiation, and stress responses via the post-transcriptional expression of target genes (11-13).

The miR-503 gene is located on human chromosome Xq26.3 $(9,14,15)$. A previous study demonstrated that the expression of miR-503 was suppressed in hepatocellular carcinoma (HCC) cells and primary tumors (16). In addition, overexpression of miR-503 inhibited tumor angiogenesis in vivo and in vitro. A further study reported that miR-503 prevented angiogenesis in tumorigenesis, and demonstrated a novel mechanism underlying hypoxia-induced basic fibroblast growth factor 2 (FGF2) and vascular endothelial growth factor A (VEGFA) expression via hypoxia-inducible factor 1- $\alpha$ (HIF1- $\alpha$ )-mediated inhibition of miR-503 (17). miR-503 was also demonstrated to be a metastasis-associated miRNA, which regulates the metastatic function of HCC cells (16). A recent study demonstrated that miR-503 was downregulated in endometrial cancer cells, and relatively high miR-503 expression levels resulted in longer survival time (18). In addition, miR-503 may act as a novel tumor suppressor gene in gastric cancer, by inhibiting epithelial-mesenchymal transition (19). 
To the best of our knowledge, no study to date has investigated the role of miR-503 in OS cells. The present study aimed to investigate the expression levels of miR-503 in OS cells, as well as to assess the effects of miR-503 on OS cell proliferation, apoptosis, migration and invasion. In addition, the association between miR-503 and FGF2 expression was also investigated.

\section{Materials and methods}

Tissue samples. Human OS and adjacent normal bone tissue samples were harvested from patients undergoing surgery in the Orthopedic Hospital of the General Hospital of PLA (Beijing, China) between April and July 2013, and were diagnosed by an independent pathologist. The patient cohort comprised 12 female and 8 male patients and their average age was 23 years. None of the patients had metastasis in the lung or any other organs at the time-point of first diagnosis. None of the patients received preoperative treatment, such as radiation therapy or chemotherapy. The present study was approved by the Ethics Committee of the Orthopaedic Hospital of the General Hospital of PLA. Written informed consent was obtained from all the subjects of the present study.

$R N A$ isolation and reverse transcription-quantitative polymerase chain reaction ( $R T-q P C R)$. Total RNA from the tissue samples and cell lines was isolated using an RNA isolation kit (Ambion Life Technologies, Carlsbad, CA, USA) according to the manufacturer's instructions. The integrity of the RNA was assessed by denaturing agarose gel electrophoresis (Regobio, Shanghai, China). RT-qPCR was performed using a TaqMan MicroRNA assay (Applied Biosystems Life Technologies, Foster City, CA, USA) and a StepOnePlus real-time PCR system (Applied Biosystems Life Technologies). All primers were obtained from the TaqMan MicroRNA assays (Regobio). Small nuclear U6 small nuclear RNA (Applied Biosystems Life Technologies) was used as an internal control. The following primers were used for reverse transcription: miR-503, 5'-GTC GTATCCAGTGCAGGGTCCGAGGTGCACTGGATACGA CCTGCAG-3' and U6, 5'-GTCGTATCCAGTGCAGGGTCC GAGGTATTCGCACTGGATACGACAAAATATGGAAC-3'. The corresponding PCR primers were as follows: Genespecific forward primers miR-503-Fwd, 5'-TGCGGTAGC AGCGGGAACAGTTC-3' and U6-Fwd, 5'-TGCGGGTGC TCGCTTCGGCAGC-3', and a universal downstream primer, 5'-CCAGTGCAGGGTCCGAGGT-3' (reverse). The RT-qPCR reaction system contained $10 \mu \mathrm{l}$ SYBR Premix Ex Taq ${ }^{\mathrm{TM}}$ II (2X), $0.8 \mu \mathrm{l}$ PCR forward primer $(10 \mu \mathrm{M}), 0.8 \mu \mathrm{l}$ Uni0miR qPCR Primer $(10 \mu \mathrm{M}), 0.4 \mu \mathrm{l}$ ROX Peference Dye II (50X), $2 \mu \mathrm{l}$ cDNA and $6 \mu \mathrm{l}$ deionized $\mathrm{H}_{2} \mathrm{O}$. The thermocycling conditions were as follows: $95^{\circ} \mathrm{C}$ for $5 \mathrm{sec}, 60^{\circ} \mathrm{C}$ for $34 \mathrm{sec}$ and amplification for 40 cycles. The PCR products were separated on a $2 \%$ agarose gel. Each experiment was conducted in triplicate. Differences in gene expression levels, expressed as fold changes, were calculated using the $2^{-\Delta \Delta C t}$ method.

Cell lines and culture conditions. The human MG-63 OS cell line was purchased from the Shanghai Institutes for Biological Sciences, Chinese Academy of Sciences (Shanghai, China). The osteosarcoma cells were cultured in RPMI 1640 medium supplemented with $10 \%$ fetal bovine serum (FBS), $2.0 \mathrm{mM}$ L-glutamine, $100 \mathrm{U} / \mathrm{ml}$ penicillin and $100 \mu \mathrm{g} / \mathrm{ml}$ streptomycin (all Regobio), and incubated at $37^{\circ} \mathrm{C}$ in a humidified incubator supplemented with $5 \% \mathrm{CO}_{2}$ and $95 \%$ air.

Cell transfection. Exponentially growing cells were seeded $\left(1.5 \times 10^{5}\right.$ cells/well) into 12 -well plates and incubated for 3 or $24 \mathrm{~h}$, followed by transfection with $30 \mathrm{nM}$ miR-503 precursor or the negative control (Ambion; Thermo Fisher Scientific, Waltham, MA, USA) with the X-treme GENE transfection reagent (Roche Applied Science, Indianapolis, IN, USA) according to the manufacturer's instructions. Transfection efficiency was evaluated $48 \mathrm{~h}$ post-transfection.

Cell proliferation assay. A total of $24 \mathrm{~h}$ post-transfection, the cells were trypsinized (Regobio), counted with a light microscope (CX4; Olympus, Japan), and seeded at a density of $4 \times 10^{3}$ cells/well into 96 -well plates. Following incubation in RPMI-1640 with $10 \% \mathrm{FBS}$ and incubated at $37^{\circ} \mathrm{C}$ with $5 \%$ $\mathrm{CO}_{2}$ for 0-7 days, a cell proliferation assay was performed using a Cell Counting kit-8 (Dojindo Molecular Technologies, Inc., Kumamoto, Japan). The solution absorbance was measured spectrophotometrically at $450 \mathrm{~nm}$ using an MRX II absorbance reader (Dynex Technologies, Inc., Chantilly, VA, USA). The experiments were performed in triplicate in three independent experiments, and the data were presented as the mean \pm standard deviation (SD).

Cell apoptosis assay. A total of $48 \mathrm{~h}$ post-transfection, the MG63 cells were harvested, resuspended, fixed, and finally resuspended in staining solution containing $1 \mathrm{mg} / \mathrm{ml}$ RNase A (Nanjing KeyGen Biotech Co., Ltd., Nanjing, China), $50 \mathrm{mg} / \mathrm{ml}$ propidium iodide (PI; Nanjing KeyGen Biotech Co., Ltd., Nanjing, China), and $0.1 \%$ Triton X-100 in phosphate-buffered saline. The stained cells were cultured in 6-well plates $\left(1 \times 10^{5}\right.$ cells/well) to $70-80 \%$ confluence. A $\mathrm{PI} /$ Annexin V-fluorescein isothiocyanate (FITC) assay (cat. no. KGA108; Nanjing KeyGen Biotech Co., Ltd.) was used to measure the number of apoptotic cells by flow cytometry. A total of $\leq 30,000$ gated events were acquired from each sample. The results were expressed as the percentage of apoptotic cells (PI and Annexin V-FITC positive) in the gated cell population. The total apoptotic rate was calculated as the early apoptotic rate plus the late apoptotic rate. An Annexin V-PI/7-AAD Apoptosis Detection kit (Nanjing KeyGen Biotech Co., Ltd.) was used to conduct the apoptosis assay of lentivirus vector-transfected cells, as described above. Each experiment was performed in triplicate, and the data were presented as the mean $\pm \mathrm{SD}$.

Cell migration and invasion assays. A cell suspension of $0.2 \mathrm{ml}$ RPMI-1640 medium supplemented with 5\% FBS was seeded into each well of the upper Transwell chamber (8 $\mu \mathrm{m}$ pore size), and pre-coated with or without Matrigel (Nanjing KeyGen Biotech Co., Ltd.). In the lower chamber, $0.6 \mathrm{ml}$ RPMI-1640 medium supplemented with 20\% FBS was added. Following incubation for $28 \mathrm{~h}$ at $37^{\circ} \mathrm{C}$ in a humidified incubator with $5 \% \mathrm{CO}_{2}$, the chambers were disassembled and the membranes were stained with $2 \%$ crystal violet for $10 \mathrm{~min}$ and placed on a glass slide. The number of cells penetrating 


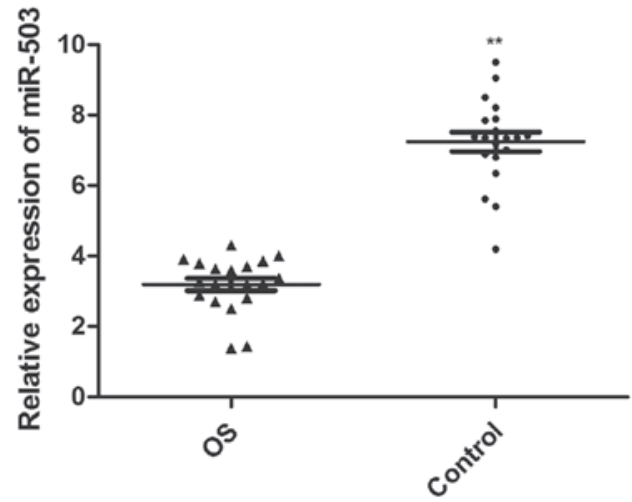

Figure 1. Expression levels of miR-503 were significantly decreased in OS tissues. The expression levels of miR-503 were quantified by reverse transcription-quantitative polymerase chain reaction in the OS (cancerous) and adjacent normal tissue samples. Each data-point represents the result for one patient. Horizontal lines represent the mean value within a group and bars represent the standard deviation. $\mathrm{P}<0.01$, vs. the control. OS, osteosarcoma; miR, microRNA.

A

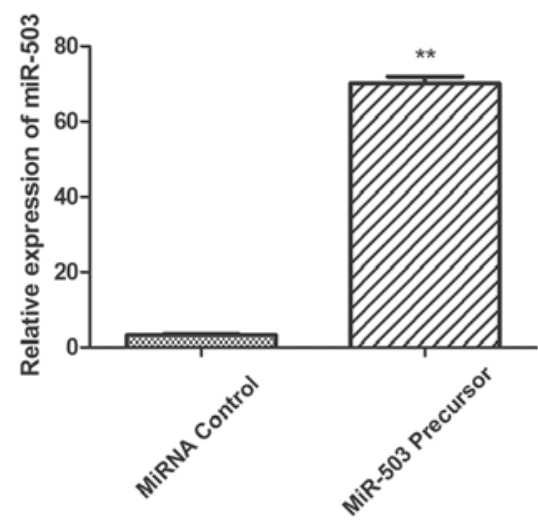

B

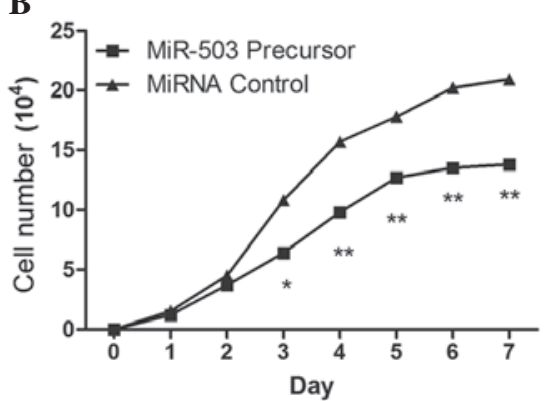

C

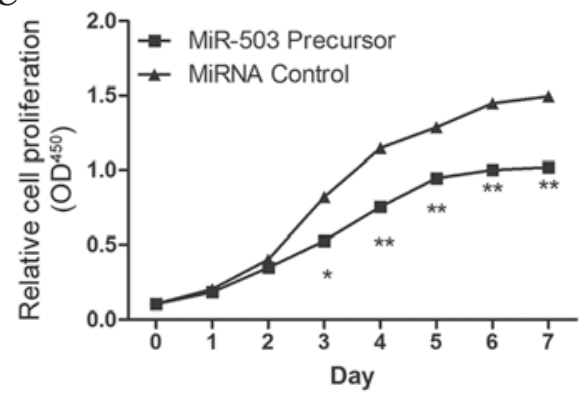

Figure 2. Overexpression of miR-503 inhibits osteosarcoma cell proliferation. (A) The expression levels of miR-503 were determined in the MG-63 cells following miR-503 precursor transfection. (B) The growth curve of MG-63 cells following miR-503 precursor transfection. (C) The cell proliferative potential was determined in MG-63 cells transfected with miR-503 precursor or negative control. $\mathrm{A}_{450}$ absorption was assayed post-transfection for 24 h. Values are expressed as the mean \pm standard deviation. ${ }^{*} \mathrm{P}<0.05 ;{ }^{* *} \mathrm{P}<0.01$. vs. control. miR, microRNA.

the membrane were counted under a light microscope (CX4; Olympus) in ten random visual fields.

Western blot analysis. Protein samples were extracted using TRIzol reagent (Invitrogen; Thermo Fisher Scientific) and then resolved on NuPAGE 4-12\% Bis Tris gels (Invitrogen) and transferred to polyvinylidene difluoride membranes (Roche Diagnostics, Basel, Switzerland). The membranes were blocked with 5\% skimmed milk/Tris-buffered saline with Tween ${ }^{\circledR} 20$, and probed with either polyclonal anti-rat tubulin $(1: 1,000$; cat. no. ab6161-100; Abcam, Cambridge, UK), monoclonal anti-mouse $\beta$-actin (1:10,000; cat. no. ab6276-100; Abcam), polyclonal anti-mouse neurophilin 2 (C-9; cat. no. sc-13117; Santa Cruz Biotechnology, Inc., Dallas, TX, USA) or polyclonal anti-goat deoxyhypusine hydroxylase (C-19; 1:1,000; cat. no. sc-55157; Santa Cruz Biotechnology, Inc.) primary antibodies. Detection was performed using horseradish peroxidase-conjugated anti-rat immunoglobulin (Ig)G (1:10,000; cat. no. ab6734-1; Abcam), anti-mouse IgG (1:10,000; cat. no. NA931 V; GE Healthcare Life Sciences, Chalfont, UK) and anti-sheep/goat IgG (1:10,000; cat. no. AB324P; EMD Millipore, Billerica, MA, USA) secondary antibodies, using an Electro Chemiluminescence (ECL) Plus detection reagent and an ECL-Hyperfilm (GE Healthcare Life Sciences).
Statistical analysis. Values are expressed as the mean \pm standard deviation, and statistical differences were compared between groups using Student's t-tests. Data were analyzed with the SPSS 18.0 statistical software package (SPSS Inc., Chicago, IL). $\mathrm{P}<0.05$ was considered to indicate a statistically significant difference.

\section{Results}

miRNA-503 is downregulated in OS tissue samples. To analyze the miR-503 expression levels in OS tissue samples, total RNA from the OS and adjacent normal bone tissue samples of 20 patients with OS were extracted, and the expression levels of miR-503 were detected. The expression levels of miR-503 in the OS tissue samples were significantly decreased (3.20 \pm 0.17$)$, compared with those in normal tissue samples (7.25 \pm 0.27 ; $\mathrm{P}<0.0001$; Fig. 1).

Effects of miR-503 overexpression on cell growth. In order to assess the effects of miR-503 on OS cell growth, the miR-503 precursor was transfected into the MG-63 cells, and cell growth at various post-transfection time points was examined. Transfection with miR-503 precursor upregulated miR-503 expression levels (Fig. 2A), and significantly inhibited 

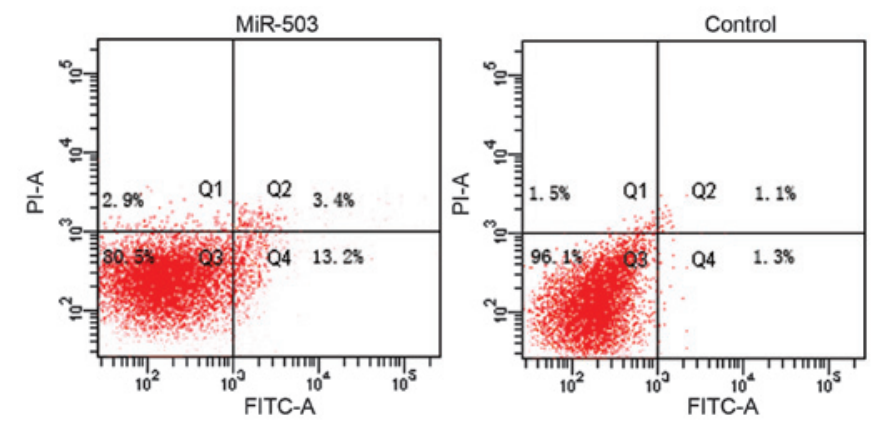

Figure 3. miR-503 induces the apoptosis of MG-63 cells. The MG-63 cells were plated and transfected with negative control or miR-503 mimics. Following transfection for $72 \mathrm{~h}$, the cells were collected and stained with Annexin V/propidium iodide. The percentages of early (low right quadrant) and late apoptotic cells (upper right quadrant) were assessed by flow cytometry. miR, microRNA; PI, propidium iodide; FITC, fluorescein isothiocyanate.
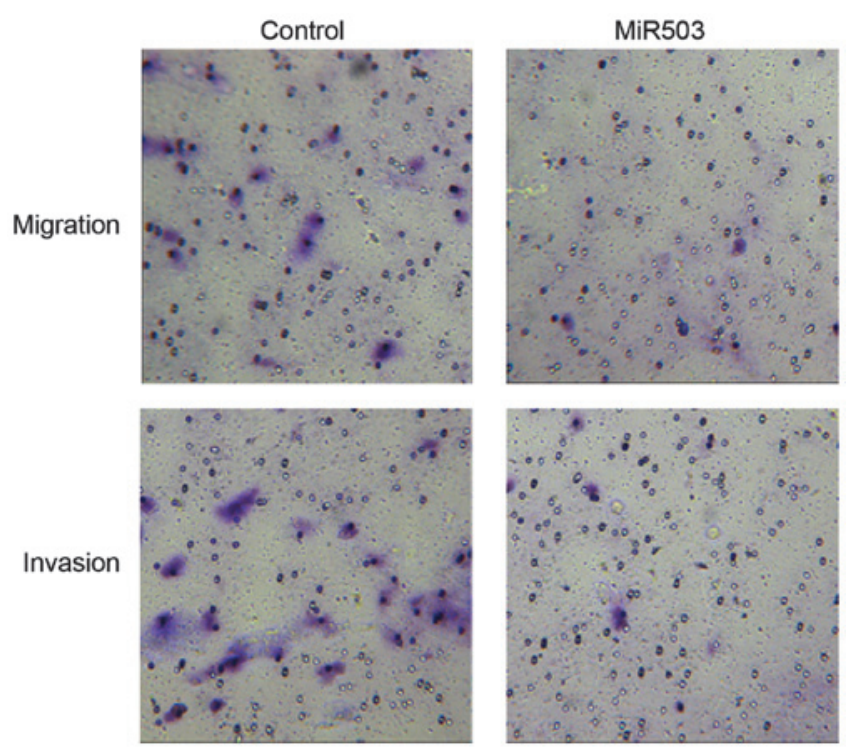

Figure 4. miR-503 inhibits the migration and invasion of MG-63 cells. Cell migration and invasion levels were analyzed by a Transwell assay $18 \mathrm{~h}$ following miR-503 or negative control transfection (magnification, x100). Cells were stained with crystal violet. miR, microRNA.

proliferation in cells post-transfection (Fig. 2B and C) 3 days post-transfection. To further explore the potential mechanism underlying the effects of miR-503 on cell growth, an apoptosis assay was conducted. Overexpression of miR-503 significantly induced cell apoptosis, as compared with negative controls (Fig. 3; P<0.05).

miR-503 inhibits MG-63 cell migration and invasion. The potential role of miR-503 with regards to MG- 63 cell migration and invasion was also investigated. MG-63 cells transfected with miR-503 precursor demonstrated markedly decreased migration and invasion levels, as compared with the negative control (Fig. 4).

miR-503 downregulates FGF2 in OS cells. The protein expression levels of FGF2 were also quantified by western blotting in the MG-63 cells transfected with miR-503 precursor. The
A

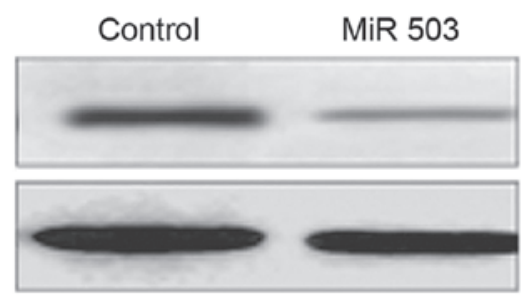

B

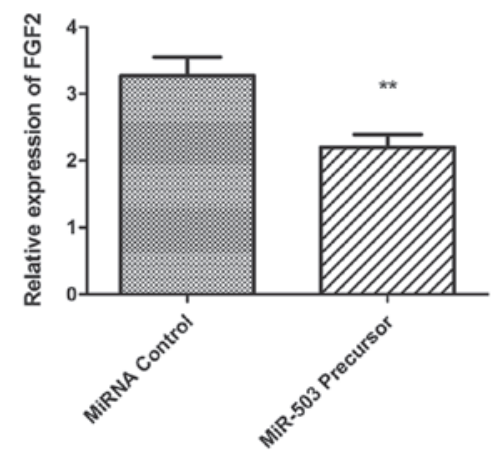

Figure 5. miR-503 inhibits FGF2 expression. (A) FGF2 protein expression levels as determined by western blotting. $\beta$-actin was used as a loading control (B) The expression levels of FGF2 in the MG-63 cells, normalized to $\beta$-actin expression levels. Values are expressed as the mean \pm standard deviation. ${ }^{* *} \mathrm{P}<0.01$, vs. the control. FGF2, fibroblast growth factor 2 ; miR, microRNA.

protein expression levels of FGF2 were significantly decreased in MG-63 cells following transfection with miR-503 precursor (Fig. 5A and B; $\mathrm{P}<0.001$ ). These results suggest that miR-503 inhibits FGF2 translation in OS cancer cells.

\section{Discussion}

The present study demonstrated that miR-503 expression was involved in the inhibition of cellular proliferation and the induction of OC cell apoptosis. In addition, miR-503 was able to inhibit the migration and invasion of OS cells, which suggested it had an important role in the metastasis of OS. Furthermore, the anticancer effects of miR-503 may be mostly due to FGF2 inhibition.

miRNAs are able to silence target genes either by direct degradation or by inhibiting their translation. Increasing evidence suggests that miRNAs may function as oncogenes or tumor suppressors in human cancer (20-22), which demonstrates their potential role as promising molecular targets for cancer therapy.

miR-503 is differentially expressed in various types of cancer (23). miR-503 is upregulated in human parathyroid carcinomas (24). Additionally, elevated miR-503 expression was associated with shorter survival rate in patients with adrenocortical carcinoma (25). Furthermore, miR-503 induced $\mathrm{G}_{1}$ phase arrest by targeting an overlapping set of cell-cycle regulators during monocyte differentiation into macrophages (26). miR-503 was also induced during myogenesis, and promoted cell-cycle arrest via cell division cycle 25A degradation (27). However, in other types of cancer, such as oral cancer and non-metastatic prostate cancer xenografts, miR-503 expression was downregulated $(28,29)$. Previous studies also revealed that miR-503 was able to silence cyclin D1, which is implicated in a variety of cancer types, 
thereby reducing S-phase cell populations and inhibiting cell growth $(18,30)$. Furthermore, a previous study demonstrated that miR-503 acted as a cell cycle regulator, and is involved in cell adhesion, angiogenesis and cell migration (31). The regulation of miR-503 expression has also been demonstrated to be important in drug resistance and metastatic traits (32). In the present study, the expression levels of miR-503 were significantly decreased in OS tissue samples, compared with normal tissue samples, and may share a similar mechanism of tumor promotion.

FGF2 is one of the most important regulators of angiogenesis $(33,34)$. The present study demonstrated that FGF2 expression is downregulated by $\mathrm{miR}-503$. The results are concordant with those of Kim et al (35), who demonstrated that miR-503 targets FGF2, and has a role in pulmonary arterial hypertension. A previous study reported that endothelial miR-15a shares similar seed sequences with miR-503, and was able to negatively regulate angiogenesis by inhibiting FGF2 and VEGFA expression (36). Furthermore, several studies have reported the anti-angiogenesis effects of miR-503 in tumorigenesis, and provide a novel mechanism for hypoxia-induced FGF2 and VEGFA expression via HIF1 $\alpha$-mediated inhibition of miR-503 $(16,17)$.

In conclusion, the present study demonstrated that miR-503 expression was involved in the inhibition of cellular proliferation, and in the induction of OS cell apoptosis. In addition, miR-503 was able to inhibit the migration and invasion of OS cells, which may be regulated by the inhibition of FGF2 expression.

\section{References}

1. Tsunemi T, Nagoya S, Kaya M, Kawaguchi S, Wada T, Yamashita T and Ishii S: Postoperative progression of pulmonary metastasis in osteosarcoma. Clin Orthop Relat Res 159-166, 2003.

2. Bacci G, Longhi A, Versari M, Mercuri M, Briccoli A and Picci P: Prognostic factors for osteosarcoma of the extremity treated with neoadjuvant chemotherapy: 15-year experience in 789 patients treated at a single institution. Cancer 106: 1154-1161, 2006.

3. Meyers PA, Gorlick R, Heller G, Casper E, Lane J, Huvos AG and Healey JH: Intensification of preoperative chemotherapy for osteogenic sarcoma: results of the Memorial Sloan-Kettering (T12) protocol. J Clin Oncol 16: 2452-2458, 1998.

4. Bacci G, Briccoli A, Longhi A, Ferrari S, Mercuri M, Faggioli F, Versari M and Picci P: Treatment and outcome of recurrent osteosarcoma: Experience at Rizzoli in 235 patients initially treated with neoadjuvant chemotherapy. Acta Oncol 44: 748-755, 2005.

5. Janeway KA, Barkauskas DA, Krailo MD, Meyers PA, Schwartz CL, Ebb DH, Seibel NL, Grier HE, Gorlick R and Marina N: Outcome for adolescent and young adult patients with osteosarcoma: A report from the children's oncology group. Cancer 118: 4597-4605, 2012.

6. Bartel DP: MicroRNAs: Genomics, biogenesis, mechanism, and function. Cell 116: 281-297, 2004.

7. Pillai RS: MicroRNA function: Multiple mechanisms for a tiny RNA? RNA 11: 1753-1761, 2005.

8. Zamore PD and Haley B: Ribo-gnome: The big world of small RNAs. Science 309: 1519-1524, 2005.

9. Bentwich I, Avniel A, Karov Y, Aharonov R, Gilad S, Barad O, Barzilai A, Einat P, Einav U, Meiri E, et al: Identification of hundreds of conserved and nonconserved human microRNAs. Nat Genet 37: 766-770, 2005

10. Berezikov E, Guryev V, van de Belt J, Wienholds E, Plasterk RH and Cuppen E: Phylogenetic shadowing and computational identification of human microRNA genes. Cell 120: 21-24, 2005 .
11. Lewis BP, Burge CB and Bartel DP: Conserved seed pairing, often flanked by adenosines, indicates that thousands of human genes are microRNA targets. Cell 120: 15-20, 2005.

12. Hwang HW and Mendell JT: MicroRNAs in cell proliferation, cell death and tumorigenesis. Br J Cancer 94: 776-780, 2006.

13. Wienholds E and Plasterk RH: MicroRNA function in animal development. FEBS Lett 579: 5911-5922, 2005.

14. Jovanovic M and Hengartner MO: miRNAs and apoptosis: RNAs to die for. Oncogene 25: 6176-6187, 2006.

15. Sewer A, Paul N, Landgraf P, Aravin A, Pfeffer S, Brownstein MJ, Tuschl T, van Nimwegen E and Zavolan M: Identification of clustered microRNAs using an ab initio prediction method. BMC bioinformatics 6: 267, 2005 .

16. Caporali A, Meloni M, Vollenkle C, Bonci D, Sala-Newby GB, Addis R, Spinetti G, Losa S, Masson R, Baker AH, et al: Deregulation of microRNA-503 contributes to diabetes mellitus-induced impairment of endothelial function and reparative angiogenesis after limb ischemia. Circulation 123: 282-291, 2011.

17. Landgraf P, Rusu M, Sheridan R, Sewer A, Iovino N, Aravin A, Pfeffer S, Rice A, Kamphorst AO, Landthaler M, et al: A mammalian microRNA expression atlas based on small RNA library sequencing. Cell 129: 1401-1414, 2007.

18. Zhou B, MaR, Si W, Li S, Xu Y, Tu X and Wang Q: MicroRNA-503 targets FGF2 and VEGFA and inhibits tumor angiogenesis and growth. Cancer Lett 333: 159-169, 2013.

19. Zhou J and Wang W: Analysis of microRNA expression profiling identifies microRNA-503 regulates metastatic function in hepatocellular cancer cell. J Surg Oncol 104: 278-283, 2011.

20. Xu YY,Wu HJ,MaHD, Xu LP, Huo Y and Yin LR: MicroRNA-503 suppresses proliferation and cell-cycle progression of endometrioid endometrial cancer by negatively regulating cyclin D1. FEBS J. 280: 3768-3779, 2013.

21. Peng Y, Liu YM, Li LC, Wang LL and Wu XL: microRNA-503 inhibits gastric cancer cell grow th and epithelial-to-mesenchymal transition. Oncol Lett 7: 1233-1238, 2014.

22. Sarver AL, Li L and Subramanian S: MicroRNA miR-183 functions as an oncogene by targeting the transcription factor EGR1 and promoting tumor cell migration. Cancer Res 70: 9570-9580, 2010.

23. Gong C, Yao Y, Wang Y, Liu B, Wu W, Chen J, Su F, Yao H and Song E: Up-regulation of miR-21 mediates resistance to trastuzumab therapy for breast cancer. J Biol Chem 286: 19127-19137, 2011.

24. Suh SS, Yoo JY, Nuovo GJ, Jeon YJ, Kim S, Lee TJ, Kim T, Bakàcs A, Alder H, Kaur B, et al: MicroRNAs/TP53 feedback circuitry in glioblastoma multiforme. Proc Natl Acad Sci USA 109: 5316-5321, 2012.

25. Zhao JJ, Yang J, Lin J, Yao N, Zhu Y, Zheng J, Xu J, Cheng JQ, Lin JY and Ma X: Identification of miRNAs associated with tumorigenesis of retinoblastoma by miRNA microarray analysis. Childs Nerv Syst 25: 13-20, 2009.

26. Corbetta S, Vaira V, Guarnieri V, Scillitani A, Eller-Vainicher C, Ferrero S, Vicentini L, Chiodini I, Bisceglia M, Beck-Peccoz P, et al: Differential expression of microRNAs in human parathyroid carcinomas compared with normal parathyroid tissue. Endocr Relat Cancer 17: 135-146, 2010.

27. Ozata DM, Caramuta S, Velazquez-Fernandez D, Akçakaya P, Xie H, Höög A, Zedenius J, Bäckdahl M, Larsson C and Lui WO: The role of microRNA deregulation in the pathogenesis of adrenocortical carcinoma. Endocr Relat Cancer 18: 643-655, 2011.

28. Forrest AR, Kanamori-Katayama M, Tomaru Y, Lassmann T, Ninomiya N, Takahashi Y, de Hoon MJ, Kubosaki A, Kaiho A, Suzuki M et al: Induction of microRNAs, mir-155, mir-222, mir-424 and mir-503, promotes monocytic differentiation through combinatorial regulation. Leukemia 24: 460-466, 2010.

29. Sarkar S, Dey BK and Dutta A: MiR-322/424 and -503 are induced during muscle differentiation and promote cell cycle quiescence and differentiation by down-regulation of Cdc25A. Mol Biol Cell 21: 2138-2149, 2010.

30. Lu YC, Chen YJ, Wang HM, Tsai CY, Chen WH, Huang YC, Fan KH, Tsai CN, Huang SF, Kang CJ, et al: Oncogenic function and early detection potential of miRNA-10b in oral cancer as identified by microRNA profiling. Cancer Prev Res (Phila) 5: 665-674, 2012 .

31. Watahiki A, Wang Y, Morris J, Dennis K, O'Dwyer HM, Gleave M, Gout PW and Wang Y: MicroRNAs associated with metastatic prostate cancer. PloS One 6: e24950, 2011.

32. Jiang Q, Feng MG and Mo YY: Systematic validation of predicted microRNAs for cyclin D1. BMC Cancer 9: 194, 2009. 
33. Cross MJ and Claesson-Welsh L: FGF and VEGF function in angiogenesis: signalling pathways, biological responses and therapeutic inhibition. Trends Pharmacol Sci. 22: 201-207, 2001.

34. Carmeliet P and Jain RK: Molecular mechanisms and clinical applications of angiogenesis. Nature 473: 298-307, 2011.

35. Kim J, Kang Y, Kojima Y, Lighthouse JK, Hu X, Aldred MA, McLean DL, Park H, Comhair SA, Greif DM, et al: An endothelial apelin-FGF link mediated by miR-424 and miR-503 is disrupted in pulmonary arterial hypertension. Nat Med 19: $74-82,2013$.
36. Yin KJ, Olsen K, Hamblin M, Zhang J, Schwendeman SP and Chen YE: Vascular endothelial cell-specific microRNA-15a inhibits angiogenesis in hindlimb ischemia. J Biol Chem. 287: 27055-27064, 2012. 